\title{
Adding Colchicine to the Antiretroviral Medication - Lopinavir/Ritonavir (Kaletra) in Hospitalized Patients with Non-Severe Covid-19 Pneumonia: A Structured Summary of a Study Protocol for a Randomized Controlled Trial
}

Nooshin Dalili, ${ }^{1,2 *}$, Alireza Kashefizadeh ${ }^{3}$, Mohsen Nafar ${ }^{1,2}$, Fatemeh Poorrezagholi ${ }^{1,2}$, Ahmad Firouzan ${ }^{1,2}$, Fariba Samadian ${ }^{1,2}$, Shiva Samavat ${ }^{1,2}$, Shadi Ziaie ${ }^{4}$ and Somayeh Fatemizadeh ${ }^{5}$

\begin{abstract}
Objectives: Colchicine is a well-known drug, which has been used for years to treat a wide range of rheumatic and inflammatory disorders. It helps break the cycle of inflammation through diverse mechanisms including reducing Intereukin-6, Interleukin-8, Tumour Necrosis Factor-alpha besides controlling oxidative stress pathways which all are important and pathologic components in the clinical course and outcome of patients infected with COVID-19. This study aims to assess the anti-inflammatory effects of colchicine in non-severe hospitalized COVID-19 patients.

Trial design: Prospective, randomized (1:1 ratio), double blind study with parallel group design.

Participants: Hospitalized patients with positive nasopharyngeal swab for COVID-19 infection (RT -PCR) and lung Computed tomography scan involvement compatible with COVID-19 pneumonia. The patients are not severely hypoxic, do not need intubation or invasive oxygenation.

Exclusion criteria: known hypersensitivity to colchicine; known hepatic failure; estimated glomerular filtration rate $\left(\right.$ eGFR) $<30 \mathrm{ml} / \mathrm{min} / 1.73 \mathrm{~m}^{2}$ (by the CKD-EPI Creatinine Equation for Glomerular Filtration Rate (GFR) which estimates GFR based on serum creatinine. ; kidney transplant recipients, using Digoxin, QTc $>450$ msec.

Participants will be recruited from inpatients at Labbafinejad Meidcal Center , Tehran, Iran.

(Continued on next page)
\end{abstract}

\footnotetext{
* Correspondence: drn.dalili@sbmu.ac.ir; dr.nooshindalili@gmail.com

'Department of Nephrology, Shahid Labbafinejad Medical Center, Shahid

Beheshti University of Medical Sciences, Boostan 9th St., Pasdaran Av, Tehran,

ran

${ }^{2}$ Chronic Kidney Disease Research Center, Shahid Beheshti University of

Medical Sciences, Tehran, Iran

Full list of author information is available at the end of the article
}

(c) The Author(s). 2020 Open Access This article is licensed under a Creative Commons Attribution 4.0 International License, which permits use, sharing, adaptation, distribution and reproduction in any medium or format, as long as you give appropriate credit to the original author(s) and the source, provide a link to the Creative Commons licence, and indicate if changes were made. The images or other third party material in this article are included in the article's Creative Commons licence, unless indicated otherwise in a credit line to the material. If material is not included in the article's Creative Commons licence and your intended use is not permitted by statutory regulation or exceeds the permitted use, you will need to obtain permission directly from the copyright holder. To view a copy of this licence, visit http://creativecommons.org/licenses/by/4.0/. The Creative Commons Public Domain Dedication waiver (http://creativecommons.org/publicdomain/zero/1.0/) applies to the data made available in this article, unless otherwise stated in a credit line to the data. 
(Continued from previous page)

Intervention and comparator: Eligible enrolled patients will be randomized into two groups. Group A will receive the antiretroviral Lopinavir/Ritonavir (Kaletra) while group B will receive Lopinavir/Ritonavir (Kaletra) + Colchicine 1.5 mg loading then $0.5 \mathrm{mg}$ twice daily orally. All patients in both groups will receive the same amounts of essential minerals, vitamins as antioxidants, and antibiotics.

Patients of both groups will be treated under optimal treatment based on the CDC and WHO guidelines and national consensus proposed in Iran including the same dosages of Lopinavir/Ritonavir, antibiotics, trace elements and antioxidants while only in group-B patients Colchicine will be added on top of this protocol.

Main outcomes: Primary: Time for clinical improvement and lung $\mathrm{C} T$ score changes 14 days after treatment. Secondary: 14 days after treatment

- C-Reactive Protein test x Neutrophil to Lymphocyte Ratio , Interleukin-6, malondialdehyde (MDA) levels reduction

- Percentage of patients who require supplemental Oxygen

- Mean hospital stay length

Randomisation: Patients will be allocated to each group (ratio 1:1) by using an online randomization tool: http://www.graphpad.com/quickcalcs/index.cfm

Blinding (masking): This will be a double-blind study in which participants and those assessing the final outcomes will be blinded to group assignment.

Numbers to be randomised (sample size): Regarding the pandemic crisis and our center capacity to hospitalize confirmed COVID-19 patients, a total of 80 patients was found to be logical to be randomized into two groups of 40- patients.

Trial Status: Recruitment is ongoing. Recruitment began on 20/03/2020 and the date by which the recruitment is anticipated to be completed is 30/05/2020.

Trial registration: ClinicalTrials.gov Identifier: NCT04360980, registered 24/04/2020.

Full protocol: The full protocol is attached as an additional file, accessible from the Trials website (Additional file 1). In the interest in expediting dissemination of this material, the familiar formatting has been eliminated; this Letter serves as a summary of the key elements of the full protocol.

Keywords: COVID-19, Randomised controlled trial, protocol, Colchicine, Oxidative Stress, Inflammation

\section{Supplementary information}

Supplementary information accompanies this paper at https://doi.org/10. 1186/s13063-020-04455-3.

Additional file 1. Full Protocol.

\section{Acknowledgements}

We want to thank all the nurses and medical staff who dedicated their time and efforts to managing patients during COVID-19 pandemic.

\section{Authors' contributions}

ND; Design and perform experiment, data analysis and co-write the paper. AK; Perform experiment. MN; Supervise the study. FP; Data collection. AF: Data Collection. FS; Contribute to sample preparation. SS: Co-write the paper SZ; Perform experiment. SF: Data analysis. The author(s) read and approved the final manuscript.

\section{Funding}

This study received funding from Chronic Kidney Disease Research Centre (CKDRC), affiliated to Shahid Beheshti University of Medical Sciences. We declare that the funding body has no role in the design of the study and collection, analysis, and interpretation of data and in writing the manuscript.

\section{Availability of data and materials}

The corresponding author will have access to the final trial dataset and the data will be available on reasonable request via sending email to drn.dalili@sbmu.ac.ir.

\section{Ethics approval and consent to participate}

Shahid Beheshti University of Medical Sciences Ethics Committee approved the trial with the ID :IR.SBMU.MSP.REC.165423 on 04/12/2020. Investigators declare this trial has received ethical approval from the appropriate ethical committee as described above. We also clarify that all participants in this study would not be included unless signing an informed consent willingly and otherwise would be excluded.

\section{Consent for publication}

Not applicable.

\section{Competing interests}

The authors declare that they have no competing interests.

\section{Author details}

${ }^{1}$ Department of Nephrology, Shahid Labbafinejad Medical Center, Shahid Beheshti University of Medical Sciences, Boostan 9th St., Pasdaran Av, Tehran, Iran. ${ }^{2}$ Chronic Kidney Disease Research Center, Shahid Beheshti University of Medical Sciences, Tehran, Iran. ${ }^{3}$ Department of Pulmonology, Shahid Labbafinejad Medical Center, Shahid Beheshti University of Medical Sciences, Tehran, Iran. ${ }^{4}$ Clinical Pharmacy Department, Faculty of Pharmacy, Shahid 
Beheshti University of Medical Sciences, Tehran, Iran. ${ }^{5}$ Department of Internal Medicine, Shahid Labbafinejad Medical Center, Shahid Beheshti University of Medical Sciences, Tehran, Iran.

Received: 24 May 2020 Accepted: 24 May 2020

Published online: 05 June 2020

\section{Publisher's Note}

Springer Nature remains neutral with regard to jurisdictional claims in published maps and institutional affiliations.

Ready to submit your research? Choose BMC and benefit from:

- fast, convenient online submission

- thorough peer review by experienced researchers in your field

- rapid publication on acceptance

- support for research data, including large and complex data types

- gold Open Access which fosters wider collaboration and increased citations

- maximum visibility for your research: over $100 \mathrm{M}$ website views per year

At $B M C$, research is always in progress.

Learn more biomedcentral.com/submissions 